\title{
Local hippocampal methamphetamine-induced reinforcement
}

\author{
Ulises M. Ricoy* and Joe L. Martinez Jr. \\ Department of Biology, University of Texas at San Antonio, San Antonio, TX, USA
}

\author{
Edited by: \\ Christian Luscher. \\ University of Geneva, Switzerland \\ Reviewed by: \\ David Belin, Université de Poitiers, \\ France \\ Christian Luscher, \\ University of Geneva, Switzerland \\ *Correspondence: \\ Ulises M. Ricoy, Department of \\ Behavioral Neuroscience, Oregon \\ Health and Science University, 3181 \\ SW Sam Jackson Park Rd L470, \\ Portland, OR 97239-3098, USA. \\ e-mail: ricoyu@ohsu.edu
}

\begin{abstract}
Drug abuse and addiction are major problems in the United States. In particular methamphetamine (METH) use has increased dramatically. A greater understanding of how METH acts on the brain to induce addiction may lead to better therapeutic targets for this problem. The hippocampus is recognized as an important structure in learning and memory, but is not typically associated with drug reinforcement or reward processes. Here, the focus is on the hippocampus which has been largely ignored in the addiction literature as compared to the nucleus accumbens (NAc), ventral tegmental area (VTA), and prefrontal cortex (PFC). The results show that METH administered unilaterally via a microdialysis probe to rats' right dorsal hippocampus will induce drug-seeking (place preference) and drug-taking (lever-pressing) behavior. Furthermore, both of these responses are dependent on local dopamine (DA) receptor activation, as they are impaired by a selective $D_{1} / D_{5}$ receptor antagonist. The results suggest that the hippocampus is part of the brain's reward circuit that underlies addiction.
\end{abstract}

Keywords: reward, hippocampus, methamphetamine

\section{INTRODUCTION}

Although the hippocampus has not traditionally been considered part of the "reward" circuitry, previous studies demonstrate the direct involvement of the hippocampus in mediating behaviors associated with drug reward. Using a classic model of reward, it was reported that rats press a lever to electrically stimulate their own hippocampus (Ursin et al., 1966). Rats will also self administer intrahippocampal dynorphin (Stevens et al., 1991) and dopamine (Stevens, 1989; pp: 83-102). Moreover, electrical self-stimulation was demonstrated in the granule cell layer (Collier et al., 1982; Collier and Routtenberg, 1984), CA3 and CA1 regions (Stevens, 1989; pp: 14-35) and entorhinal cortex (Collier et al., 1977, 1982; Collier and Routtenberg, 1984) of the hippocampal formation. In addition to glutamatergic input from the PFC, the NAc receives glutamatergic afferents from the subiculum of the hippocampal formation (Groenewegen et al., 1987) and brief trains of electrical stimulation in the subiculum can evoke a significant increase in DA efflux in the NAc which persists for 20-30 min (Blaha et al., 1997; Taepavarapruk et al., 2000). Interestingly, subicular electrical stimulation has also been shown to reinstate drug-seeking behavior (Vorel et al., 2001; Taepavarapruk and Phillips, 2003) whereas hippocampal-subicular pharmacological inactivation reduces drug-seeking and drug-taking behavior in rodents (Sun and Rebec, 2003; Black et al., 2004). Besides, using another classic model of reward, it was shown that morphine infusions into hippocampus induces a conditioned place preference (CPP) in rats (Corrigall and Linseman, 1988). Similarly, pharmacological hippocampal inactivation disrupts the acquisition of systemic cocaine-mediated CPP (Meyers et al., 2003, 2006). Moreover, associating context-spatial locations with drug rewards is fundamental to survival in natural environments and requires the integrity of the hippocampus and ventral striatum (Lansink et al., 2009).

In addition, long-term neural adaptations resulting from repeated drug exposure involve an associative learning process (Wolf, 2002) that may require the hippocampus (Berke and Hyman, 2000; Berke and Eichenbaum, 2001; Nestler, 2001, 2002; Robbins and Everitt,
2002; Berke, 2003). The hippocampus shows various functional states under the control of neuromodulators (Hirase et al., 2001). The role of DA has been less extensively studied because of the early view that the hippocampus did not receive a significant dopaminergic innervation (Loy et al., 1980). It is now recognized that the hippocampus does receive such innervation (Gasbarri et al., 1994a,b). Anatomical and chemical observations indicate that hippocampal areas CA3, CA1 and subiculum receive DA projections from the VTA 10 (Scatton et al., 1980; Swanson, 1982; Verney et al., 1985) and express high levels of $\mathrm{D}_{1}$ - and $\mathrm{D}_{2}$-like receptors (Bischoff et al., 1980; Martres et al., 1985; Bruinink and Bischoff, 1986) and there has been progress in understanding its function.

Taken together, current evidence suggests that the neural mechanisms underlying learning and memory are also a central component of the classic reward circuitry underlying drug addiction (Kelley, 2004; Hyman et al., 2006). Specifically, synaptic plasticity has provided clear evidence that $\mathrm{DA}$ via $\mathrm{D}_{1} / \mathrm{D}_{5}$ receptors affects long-term potentiation (LTP), a form of synaptic plasticity thought to encode long-term memory. At the cellular level, DA agonists can affect synaptic transmission in the hippocampus and modulate the perforant path input to the hippocampus (Otmakhova and Lisman, 1996, 1998, 1999). Thus, synaptic plasticity may function as a mechanism by which psychoactive drugs can initiate signal transduction cascades that sustain drug reward or craving (Nestler and Aghajanian, 1997; Nestler, 2002; Kelley, 2004). At the behavioral level, the local application of a $D_{1} / D_{5}$ receptor antagonist into the dorsal hippocampus impairs learning (acquisition) and memory (expression) of drug-seeking behaviors such as systemic cocaine and morphine CPP (Rezayof et al., 2003; Zarrindast et al., 2005; Zornoza et al., 2005a,b), which suggest that despite the clear pharmacological differences between psychostimulants and opiates, the hippocampus may be playing a key role in drug reward circuitry.

A unifying mechanism that would explain how the hippocampus may be playing such role in the drug reward circuitry is via the activation of local $D_{1} / D_{5}$ receptors which are known 
to enhance hippocampal LTP in vivo (Li et al., 2003). Enhanced hippocampal LTP translates to an elevated CA1 output to medium spiny neurons in the NAc. Medium spiny neurons display a bistable subthreshold membrane property (O'Donnell and Grace, 1995) and the up-state can be induced by enhanced activation of the hippocampal afferent fibers (O'Donnell and Grace, 1998). The NAc medium spiny cell's up-state in turn removes ventral pallidum (VP) tonic inhibition onto VTA DA neurons (Lisman and Otmakhova, 2001; Lisman and Grace, 2005), resulting in disinhibition of VTA DA cells. The activity of these cells is thought to be a key event in the early stages of drug addiction. A recent study showed that the activation of hippocampal afferents to the NAc modulate DA neuron responsivity by regulating the intensity of phasic neuron activation (Lodge and Grace, 2006).

The objective of this study was to investigate the role of the hippocampus in mediating drug reinforcement. Specifically, we examined whether the intrahippocampal dialysis of methamphetamine (METH) into the dorsal hippocampus produces drug-seeking (CPP) and drug-taking (self administration) behavior in rodents. Further, we examined the role of local $\mathrm{D}_{1} / \mathrm{D}_{5}$ receptors in METH-induced intrahippocampal drug-seeking and drug-taking behavior.

\section{MATERIALS AND METHODS \\ ANIMALS}

The animals used in this study were 275-325 g male Sprague-Dawley rats (Harlan, Raleigh, NC, USA). The animals were housed individually in standard plastic laboratory cages $(20 \mathrm{~cm} \times 20 \mathrm{~cm} \times 32 \mathrm{~cm})$, on a 12:12 hour light:dark cycle (lights on at 07:00 hours) with access to food and water ad libitum. After arrival, the animals were allowed 5 days to acclimate before any experimental procedures began. All animals were handled daily for 15 min during these 5 days. The animal use protocols were approved by the Institutional Animal Care and Use Committee at the University of Texas at San Antonio.

\section{SURGERY}

The animals were anesthetized with intraperitoneal (IP) injections of Nembutal $(50 \mathrm{mg} / \mathrm{kg}$; Abbott Laboratories, North Chicago, IL, USA). The animals were mounted in a stereotaxic apparatus and their skulls were exposed. A plastic guide cannulae with a stainless steel dummy cannulae (CMA/Microdialysis, Acton, MA, USA) was directed at either the right dorsal hippocampus (coordinates: AP $-3.5 \mathrm{~mm}$ from bregma, ML $2.5 \mathrm{~mm}$ from the midsagittal suture, DV $-2.8 \mathrm{~mm}$ from the skull surface) or lateral cortex (CTX) (coordinates: AP $-3.5 \mathrm{~mm}$ from bregma, ML $5.5 \mathrm{~mm}$ from the midsagittal suture, $\mathrm{DV}-2.8 \mathrm{~mm}$ from skull surface). All coordinates were based on (Paxinos and Watson, 2007). The hippocampal coordinates used in this study are consistent to regions rich in DA receptor expression and function (Bischoff et al., 1980; Scatton et al., 1980; Bruinink and Bischoff, 1986). Following implantation, the guide cannulae was anchored to the skull using three skull screws and dental cement. Animals received an intramuscular injection $(0.3 \mathrm{ml})$ of penicillin $(22,500 \mathrm{U} / \mathrm{ml})$ into each thigh after the surgery to prevent infection and were given water treated with acetaminophen $(0.32 \mathrm{mg} / \mathrm{ml})$ for 3 days to reduce post surgery discomfort. Animals were allowed 3-7 days to recover from surgery before experimental procedures were initiated.

\section{ANATOMICAL CONTROL}

A separate group of animals with probe placements in the lateral distal cortex was added as an anatomical control. These animals were trained for CPP and self administration procedures just as the other groups. Anatomical control regions used in this study included the overlying cortex directly above the hippocampus (CTXa) and the somatosensory cortex lateral to the hippocampal coordinates used in this study (CTXb).

\section{DRUGS}

The Ringer's vehicle solution (Baxter, Deerfield, IL, USA) was composed of: $6 \mathrm{mg} / \mathrm{ml} \mathrm{NaCl}, 3.1 \mathrm{mg} / \mathrm{ml}$ sodium lactate, $0.3 \mathrm{mg} / \mathrm{ml} \mathrm{KCl}$, and $0.2 \mathrm{mg} / \mathrm{ml} \mathrm{CaCl}$. Dextro-methamphetamine hydrochloride (METH, Sigma Chemical Co., St. Louis, MO, USA) was dissolved in Ringer's solution at a concentration of $10 \mu \mathrm{g} / \mu \mathrm{l}$ and was prepared daily. The dopamine $\mathrm{D}_{1} / \mathrm{D}_{5}$ receptor selective antagonist $\mathrm{SCH} 23390$ (100 and $250 \mu \mathrm{M} / \mu \mathrm{l})$ was dissolved in Ringer's solution and was prepared daily (Sigma Chemical Co., St. Louis, MO, USA). Radiolabeled $\left[{ }^{3} \mathrm{H}\right]$ dextro-methamphetamine $(1.5 \mathrm{mM})$ was obtained from the National Institute on Drug Abuse, Baltimore, MD, USA.

\section{APPARATUS}

CPP was examined using Plexiglas chambers $(70 \mathrm{~cm}$ $\mathrm{W} \times 22 \mathrm{~cm} \mathrm{D} \times 33 \mathrm{~cm} \mathrm{H}$ ) which consisted of two end chambers $(26 \mathrm{~cm} \mathrm{~W} \times 22 \mathrm{~cm} \mathrm{D} \times 33 \mathrm{~cm} \mathrm{H})$ and one smaller center chamber $(18 \mathrm{~cm} \mathrm{~W} \times 22 \mathrm{~cm} \mathrm{D} \times 33 \mathrm{~cm} \mathrm{H}$ ) (San Diego Instruments, San Diego, CA, USA). Each of the three chambers had four photo beams and sensors. The CPP apparatus was controlled by software (provided by San Diego Instruments) and was connected to a computer which ran the software Photobeam Activity System (PAS). The CPP apparatus was experimentally manipulated to create a bias toward the left black compartment in contrast to a right white compartment. The CPP apparatus also included a neutral gray center smaller compartment. Previous work from our laboratory has shown that rats express a bias for a particular side, with most preferring the dark black compartment. Self administration was examined using computer-controlled operant chambers housed inside sound attenuating boxes (Coulbourn Instruments, Allentown, PA, USA). Inside the sound attenuating chamber, a Skinner chamber housed the hardware-apparatus. One wall of each chamber contained two levers, a cue light above one lever, and a house light. One lever was designated as the active lever and when pressed activated a pump via a swivel. Activation of the pump initiated dialysis for $60 \mathrm{~s}$. The other level was inactive and responding on this lever had no programmed consequence. Inactive lever presses were used as an index of overall locomotor activity. The houselight illuminated the inside of the chamber throughout the behavioral procedure.

\section{CONDITIONED PLACE PREFERENCE PARADIGM}

The CPP paradigm consisted of three phases: preconditioning, conditioning and post-conditioning. For the pre and post conditioning phases, animals were placed in the neutral gray center compartment and the sliding doors were removed to allow equal access to the entire apparatus for $15 \mathrm{~min}$. The amount of time each rat spent in each compartment was monitored to determine the initial preference. During the conditioning phase, the 
animals received either a Ringer's vehicle or METH (drug delivery described below) solution dialysis for the first 10 of the 30 min sessions for eight conditioning sessions in a counterbalanced design. Specifically, each animal received four METH dialyses in their initially non-preferred side (drug-paired side) and four vehicle (Ringer's) dialyses in their initially preferred side (vehicle-paired side). Animals were confined to the appropriate compartment for the entire conditioning session (30 min) blocking access to the neutral compartment by the sliding door. The data reported herein showed that rats initially expressed a bias for a particular side, with most preferring the dark black compartment. For the post-conditioning tests, the animals were allowed to access the entire apparatus in a drug free-state or in the presence of local SCH 23390. The drug doses and dialysis procedures are described below. The CPP apparatus had a biased design (i.e., drug was administered on the initially non-preferred side) and thus the relative amount of time spent in each compartment before vs. after conditioning was used to assess the CPP. The CPP data reported here is shown as the "time difference" and such was calculated by subtracting the time spent in the initially non-preferred side of the apparatus (drug-paired) and the time spent in the same side during the post-conditioning test. Therefore, a positive value is indicative of "reward" and a negative value is sometimes interpreted as "aversion" (Bardo et al., 1996; Bardo, 1998). It is important to mention that overall METH treated rats spent significantly more time in the initially non-preferred compartment than the initially preferred compartment following drug conditioning suggesting a true reward measurement and ruling out an anxiety reduction effect (data not shown). For a full discussion on this topic see (Tzschentke, 1998).

\section{SELF ADMINISTRATION PARADIGM}

All animals trained in CPP were trained to lever press for intrahippocampal dialyses of METH. Operant conditioning consisted of daily 30 min sessions for 8 days. At the beginning of each session following a 45-s delay, the first trial of the session began by having a cue-light turned on above the active lever which remained on for $60 \mathrm{~s}$ signaling drug availability. During this drug available period, a single active lever press activated the pump. The activation of the pump initiated a 60 -s dialysis period. After the pump turned off, it remained off for another $60 \mathrm{~s}$ (inter-trial interval) and then another trial began. If the "active" lever was not pressed during the $60 \mathrm{~s}$ drug availability period, the cue-light turned off and remained off for another $60 \mathrm{~s}$ and then again turned on for another trial. During the cue-light illuminated drug availability period (duration of the session from 0 to $59 \mathrm{~s}$ ), a single active lever-press resulted in delivery of either $2 \mu \mathrm{l}$ of Ringer's or METH solution through the probe into the hippocampus. The active lever presses that activated the pump were defined as "lever presses yielding dialysis" for the data presentation. Pressing of the active lever after the pump was activated had no consequence but was measured to display conditioned behavior and these responses were defined as "lever presses during dialysis". The last three sessions of self administration, the antagonist SCH 23390 was co-administered with METH to either the hippocampus or the CTX (depending on group). During the conditioning session an inactive lever was present and was always extended. A bar press on the inactive lever had no programmed consequence and was called "inactive lever presses." The inactive lever presses were measured to monitor of baseline lever presses in the absence of reinforcement (i.e., general motor activity).

\section{DRUG DELIVERY VIA REVERSE MICRODIALYSIS}

All rats were taken from the colony room and brought to the experimental room 60-90 min prior to each daily session (CPP or self administration). The microdialysis probes were pre-loaded by connecting them to the infusion pumps and continuously dialyzed with either Ringer's vehicle or METH solution $(10 \mu \mathrm{g} / \mu \mathrm{l})$ at a flow rate $2.0 \mu \mathrm{l} / \mathrm{min}$. The pre-loading process was evident because solution appeared on the outflow side of the probe, which took approximately $10 \mathrm{~min}$. For all experiments, a new pre-loaded microdialysis probe was inserted through the guided cannulae prior to every session. The tip of the microdialysis membrane is closed and thus only the lateral sides of the microdialysis probe are in contact with surrounding tissue and are accessible to dialysis. This is important to mention as probe placements are within dorsal hippocampal regions where DA receptors are expressed. For experiments where SCH 23390 was used, the antagonist SCH 23390 ( 100 and $250 \mu \mathrm{M} / \mu \mathrm{l}$ ) was dissolved in either Ringer's solution or METH.

\section{HISTOLOGY}

Cannulae placement was determined from coronal, thionin-stained $50 \mu \mathrm{m}$ sections. After completion of behavioral testing, each animal was euthanized with an overdose of Nembutal (100 mg/kg, IP).

\section{ANATOMICAL SPECIFICITY}

The following experiment was designed to examine if METH diffusion within the hippocampus is spatially limited. The Hippocampus of those animals that received $\left[{ }^{3} \mathrm{H}\right] \mathrm{d}$-methamphetamine was further dissected into three regions $\left(1,2\right.$ and 3 ) for the $\left[{ }^{3} \mathrm{H}\right]$ d-methamphetamine diffusion experiment explained below. The dissection consisted in separating the right hemisphere and removing the overlying cortex. The overlying cortex (CTXa) and the lateral cortex $(\mathrm{CTXb})$ to the hippocampus were distal regions and used in this experiment as an anatomical control. All dissected brain regions were examined using a scintillation counter to measure disintegrations per minute and thus calculate counts per minute (cpm) per microliter of tissue to determine local brain drug concentration following $\left[{ }^{3} \mathrm{H}\right] \mathrm{METH}$ dialysis. To determine how much radio-labeled METH would dialyze through the microdialysis probe we would be using, we first prepared a $10-\mu \mathrm{g} / \mu \mathrm{l}$ stock METH solution in $1.0 \mathrm{ml}$ Ringer's vehicle by adding $5.4 \mu \mathrm{l}$ out of the stock $\left[{ }^{3} \mathrm{H}\right]$ radioactivelabeled METH (1.5 mM). This METH mixture was the solution that went in the syringe and defined as the dialysate. Two additional control $5.0 \mu \mathrm{l}$ aliquots were made from the stock METH mixture solution and these were placed in scintillation vials. To one of these control background vials, a comparable hippocampus brain sample was added as a tissue quenching effect. To these two additional samples we added a known amount of radioactive-labeled METH and these were used as controls to relate radiation quantification to local brain concentration. The METH mixture dialysate contained $180,391 \mathrm{cpm} / \mu \mathrm{l}$. This is the dialysate that was dialyzed in vivo for either 10 or $30 \mathrm{~min}$ (data not shown). Although all dialyses in behavioral testing did not exceed $10 \mathrm{~min}$, we purposely tripled the duration $(30 \mathrm{~min})$ to show that even at long dialysis durations, 
spatial diffusion is discrete. Animals were decapitated 30 min after completing the 10 or 30 min dialysis period and their brains rapidly removed for dissection (as described above) and the tissue was placed in glass vials. Each vial contained either a known amount of METH solution as background or the tissue of interest. To each vial, we added $10 \mathrm{ml}$ of scintillation fluid (Aquasol) and using a Pasteur pipette the tissue was broken up and homogenized before placing the vials in the scintillation counter (Beckman LS2800, Beckman Instruments Inc., Fullerton, CA, USA).

\section{STATISTICAL ANALYSIS}

Only animals with correct probe placements were included in the analysis. Approximately, $80 \%$ of all animals had accurate probe placements. Statistical analyses (one-way and two-way ANOVAs) were used to determine statistical significance of the treatment
(METH or Ringer's) as the between factor, and days of training or "time spent" (pre and post-conditioning in drug-paired side) as the within factor. The Tukey test was used to determine significance during preplanned post hoc pair-wise comparison analysis.

\section{RESULTS}

\section{HISTOLOGY}

Figure 1 inset illustrates a coronal section of the brain of a representative rat that received multiple dialysis probe insertions (17) after completing both CPP and self administration experiments. Animals included in the anatomical control groups had stereotaxic coordinates directed towards the secondary somatic sensory cortex/barrel cortex and were included only if they had accurate placements. Approximately $20 \%$ of all completed surgical placements to animals were excluded based on inaccurate
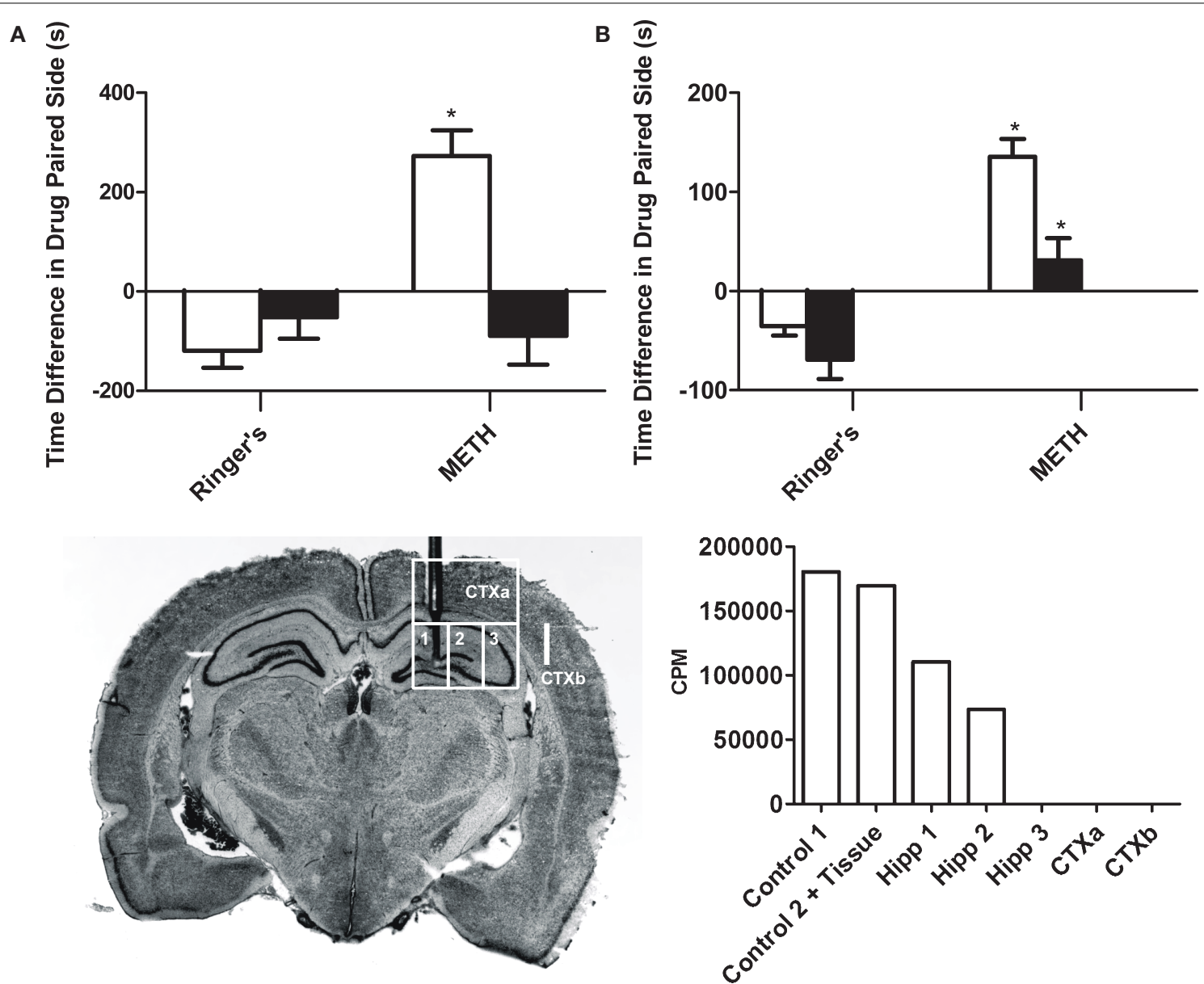

FIGURE 1 | Intrahippocampal METH-induced CPP is spatially discrete and modulated via local $\mathbf{D}_{1} / \mathbf{D}_{5}$ receptors. (A) The effects of intrahippocampal METH $10 \mu \mathrm{g} / \mu \mathrm{l}(n=12)$ or Ringer's $(n=10)$ on CPPTest 1 (white bars) and the effects of local SCH 23390 application (black bars) prior to Test 2 (to examine CPP Expression) of either Intrahippocampal METH trained rats for CPP $(n=7)$ or vehicle $(n=6)$. (B) The effects of intrahippocampal METH $10 \mu \mathrm{g} / \mu \mathrm{l}(n=6)$ or Ringer's ( $n=5)$ on CPPTest 1 (white bars) and the effects of local SCH 23390 co-application with METH (black bars) during conditioning (to examine CPP Acquisition) of either Intrahippocampal METH CPP $(n=6)$ or Ringer's $(n=6)$.
The inset at the bottom left shows a coronal section of the brain of a representative rat that received multiple dialyses. Hippocampal sub regions ( $a, b$ and c) and cortical areas (CTXa) and (CTXb) used for the scintillation counter experiment are labeled. The inset at the bottom right shows scintillation counter measurements (CPM) of $\left[{ }^{3} \mathrm{H}\right] \mathrm{METH}$ revealing limited diffusion within hippocampus during a 10-min dialysis where the microdialysis probe was located $(1,2,3)$. Overlying tissue (CTXa) and lateral regions (CTXb) did not reflect any CPM revealing limited diffusion. The symbol * represents a statistical difference from all the other groups $(P<0.05)$. 
cannulae placement and dialysis failures that occurred during the experiments. Figure 1 inset also illustrates the hippocampal and cortical regions dissected for the radio-labeled METH diffusion experiment.

\section{ANATOMICAL SPECIFICITY}

This experiment reveals that the intrahippocampal dialysis of METH into the dorsal hippocampus is spatially discrete as diffusion within the hippocampus is limited (Figure 1 inset). The hippocampus was dissected into three regions (1,2 and 3$)$. The overlying cortex (CTXa) and the cortex (CTXb) lateral to the hippocampus were distal regions used as anatomical controls. All dissected brain regions were examined using a scintillation counter to measure disintegrations per minute and thus calculate counts per minute per microliter of tissue to determine local brain drug concentration. Theoretically, in $10 \mathrm{~min}$ (duration of typical drug dialysis in CPP experiments) at a $2-\mu \mathrm{l} / \mathrm{min}$ flow rate, $20 \mu \mathrm{l}$ are dialyzed. Using a scintillation counter we measured that $180,391 \mathrm{cpm}$ of HOT METH were present in $1 \mu \mathrm{l}$ of dialysate and such counts considered $100 \%$ of available METH dialysis counts per microliter (see Figure 1 bottom right inset "No Tissue" Column). Following a 10 min intrahippocampal dialysis with the METH dialysate, we found that $183,852 \mathrm{cpm}$ were measured (see Figure 1 inset, adding columns $3,4,5)$. We can calculate that up to $20 \mu \mathrm{l}$ are dialyzed, yielding an estimated $9192 \mathrm{cpm} / \mu$ l during dialysis which is roughly $5 \%$ of the total counts found in $1 \mu \mathrm{l}$ of the original METH dialysate mentioned above. Such theoretical in vivo approximation is comparable to the $10 \%$ microdialysis recovery estimates from in vitro studies (Rodriguez et al., 2008) if considering that the active membrane length used in that study was $1.5 \mathrm{~mm}$ compared to $1.0 \mathrm{~mm}$ in this study. Furthermore, if assuming a similar radial diffusion of 0.5 to a 1-mm from the wall of the microdialysis probe's membrane as estimated in other microdialysis studies (Wozniak et al., 1991; Gonzales et al., 1998), then the total volume of tissue affected would be approximately $1 \mu \mathrm{l}$ of tissue (excluding probe displacement volume). Based on volumetric studies, the unilateral dorsal hippocampal volume would be equivalent to $50 \mu$ where the probe placement was positioned (Kalisch et al., 2006). Further if we concentrate on the precise location of the probe location, we can then calculate that during a 10 -min dialysis session, a total of $110,369 \mathrm{cpm}$ (see Figure 1 inset, Column 3) divided by the approximated hippocampal volume $(\sim 50 \mu \mathrm{l})$ yields total METH counts per microliter of tissue or 2207.38 METH cpm/ $\mu$ l of tissue. Thus, the mean total counts of METH per microliter of tissue are $2207.38 \mathrm{cpm} / \mu \mathrm{l}$. In other words, the mean total counts after a 10-min intrahippocampal dialysis are $1.2 \%$ of that found in $1 \mu \mathrm{l}$ of the dialysate, and this was defined as the diffusion factor. Therefore the mean concentration of METH in the hippocampal tissue following a 10-min dialysis with $53.3 \mathrm{mM}(10 \mu \mathrm{g} / \mu \mathrm{l})$ would be $0.625 \mathrm{mM}$ or $625 \mu \mathrm{M}$ by multiplying by the diffusion factor above. This is equivalent to a total of $5.8 \mu \mathrm{g}$ of METH after a 10 -min dialysis or $\sim 34 \mathrm{nmol}$ in $50 \mu \mathrm{l}$ of tissue. The diffusion factor calculated here to estimate local brain drug concentration is a similar attempt as to previous experimental approaches with reverse microdialysis as a method of brain drug delivery (Wise et al., 1995; Robinson et al., 2000; Vezina et al., 2002; Crespo et al., 2006).

\section{CONDITIONED PLACE PREFERENCE EXPERIMENTS}

The objective of this experiment is to determine if METH administration into the dorsal hippocampus is rewarding as measured by CPP. Here we show (Figures 1A,B), that animals receiving METH reveal a positive CPP score (Test 1: METH group white bars) as compared to the Ringer's vehicle treated animals. Further, the METH-induced preference is completely blocked if the $\mathrm{D}_{1} / \mathrm{D}_{5}$ antagonist (SCH 23390) is administered prior to the CPP postconditioning Test 2, (METH black bar; Figure 1A) to examine CPP expression. We also demonstrate that if the administration of the local antagonist occurs during conditioning to examine $\mathrm{CPP}$ acquisition, the METH-induced CPP effect is reduced (METH black bar; Figure 1B). We then asked if the $D_{1} / D_{5}$ antagonist would also block the already reduced METH-induced CPP expression observed when the antagonist was co-administered with METH during conditioning (Figure 2A; white bars). Our results reveal that the local application of SCH 23390 prior to Test 2 (black bars) failed to block the reduced METH-induced effect in animals with prior exposure to the antagonist (Figure 2A; black bar). Not surprisingly, just as before, the application of SCH 23390 prior to Test 2 (black bars) completely blocked the positive METH-induced CPP in METH treated animals without prior exposure to the antagonist (Figure 2A; black bar).

Furthermore, the METH-induced effect is specific to the hippocampus as the dialysis of METH into the lateral Cortex (CTXb; see Figure 1 inset) failed to elicit a positive CPP (Figure 2B; white bars). Additionally, we report that a lower dose $(100 \mu \mathrm{M})$ of the antagonist significantly blocks METH-induced CPP expression (retrieval) in animals with microdialysis probes in their hippocampus (Figure 2B; black bars).

\section{LOCOMOTOR ACTIVITY (SHUFFLING BEHAVIOR)}

This purpose of this experiment is to show that that the usage of the selective $\mathrm{D}_{1} / \mathrm{D}_{5}$ antagonist (SCH 23390) used in this study to significantly block the METH-induced CPP does not significantly affect locomotor activity as we measured shuffling behavior (the number of crosses across the three compartments on preconditioning (white bar) and post conditioning Test 1 (gray bar) and Test 2 (black bar; Figure 2C).

\section{SELF ADMINISTRATION EXPERIMENTS}

Earlier, we demonstrated that the application of METH directly into the hippocampus is rewarding as measured by CPP. In this experiment, we supplement the initial CPP findings by revealing that intrahippocampal METH also sustains lever pressing behavior (Figures 3A,B). Interestingly, the lever pressing behavior during the dialysis period (see Section "Materials and Methods") is far greater than the active presses yielding dialysis upon pump activation (data included in overall average lever presses shown in Figure 4) suggesting a local METH-induced positive reinforcement behavior. The local application of the $\mathrm{D}_{1} / \mathrm{D}_{5}$ antagonist $\mathrm{SCH}$ $23390(100$ and $250 \mu \mathrm{M})$ during the last 3 days impaired overall active lever pressing behavior in the METH treated animals (Figures 4A,B). Further, it is shown METH-induced lever pressing behavior is specific to the hippocampus (Figures $3 \mathrm{~A}$ and $4 \mathrm{~A}$ ) and not the cortex (Figures 3B and 4B). 


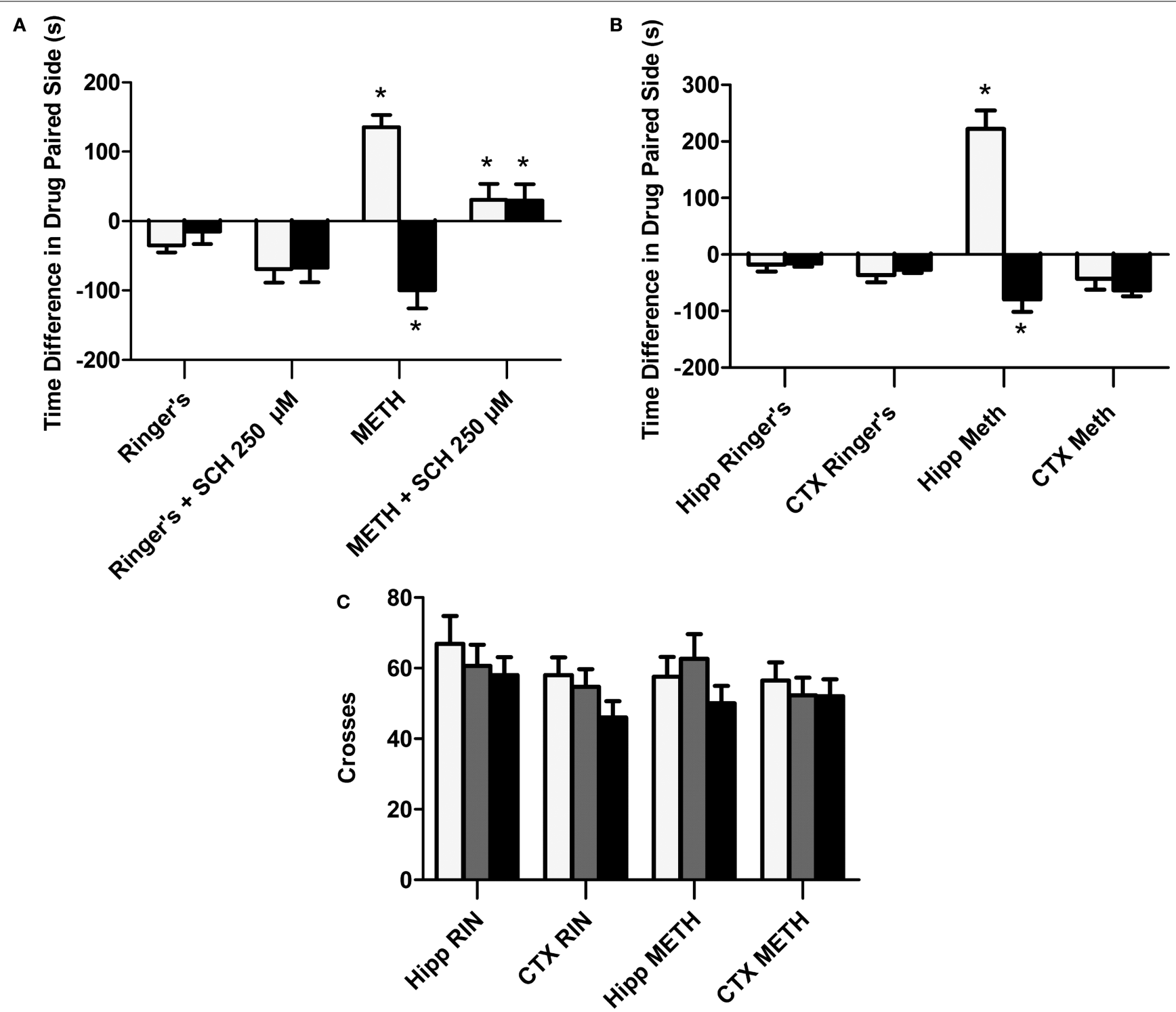

FIGURE 2 | Role of local $D_{1} / D_{5}$ receptors in the acquisition and expression of intrahippocampal METH CPP. (A) The effects of intrahippocampal METH $\mu \mathrm{g} / \mu \mathrm{l}(n=6)$ or Ringer's $(n=5)$ on CPPTest 1 and the effects of local SCH 23390 on CPP acquisition (Test 1) and CPP expression (Test 2) of intrahippocampal METH CPP $(n=6)$ or Ringer's vehicle $(n=6)$. (B) METH only induces CPP in the hippocampus and not the cortex (CTX). The effects of intracranial METH (hippocampus $n=13$ or CTX $n=10$ ) or Ringer's (hippocampus $n=11$ or CTX $n=10$ ) on CPP and local SCH 23390 on CPP acquisition (Test 1) and expression (Test 2) of intrahippocampal METH CPP. The symbol * represents a difference from all other groups $(P<0.05)$. (C) Local hippocampal $D_{1} / D_{5}$ antagonism does not affect locomotor activity. White bar represents crosses during pre conditioning test. The gray bar is activity during the first drug-free test while the black bar is activity in the presence of the $D_{1} / D_{5}$ antagonist $(100 \mu \mathrm{M})$.

\section{DISCUSSION}

\section{DRUG DELIVERY VIA REVERSE MICRODIALYSIS ADVANTAGES}

In this study, a microdialysis probe was used to deliver the reinforcer by reverse dialysis to reduce the high pressure commonly caused by multiple infusions with open-ended cannulaes. The effects involved with multiple infusions into discrete brain regions could be attributed to a physical-chemical interaction on neuronal fibers, not necessarily due to direct synaptic action. To respond to this potential problem; the use of reverse microdialysis offers the advantage of maintaining the drug concentration along the membrane due to its slow flow rate with the volume being dialyzed over a long period of time and without spread beyond the site of interest (Quan and Blatteis, 1989). Thus, the reverse microdialysis technique offers reliable drug diffusion over the desired area without pressure injection variability since there is no volume transfer into the brain evoking a true synaptic action rather than a physical-chemical interaction (Bazzett et al., 1991). Not surprisingly, the reverse microdialysis drug delivery method has provided a powerful technique for the study of local drug action and been used extensively in the brain and other tissues and has been thoroughly reviewed in the literature (Hocht et al., 2004, 2007; Plock and Kloft, 2005). The drug concentrations used in this 


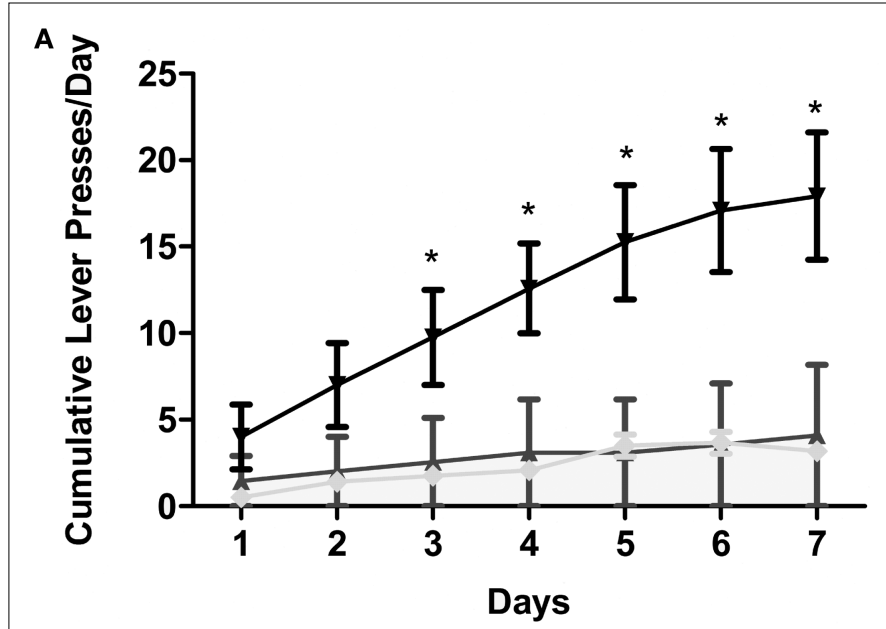

FIGURE 3 | Intrahippocampal METH sustains self administration.

(A) Cumulative lever presses per day on the active and inactive levers during the 30-min test sessions across 7 days. Rats in the Ringer's $(n=11)$ and METH $10 \mu \mathrm{g} / \mu \mathrm{l}$ ( $n=12$ ) groups were co-treated with $250 \mu \mathrm{M} \mathrm{SCH}$ during days 5-7. METH $10 \mu \mathrm{g} / \mu \mathrm{l}$ group active lever presses were significantly greater than Ringer's group active lever presses from day 3 onward. METH group: upside-down black triangles; METH inactive: light gray diamonds; Ringer's: dark gray triangles. (B) METH

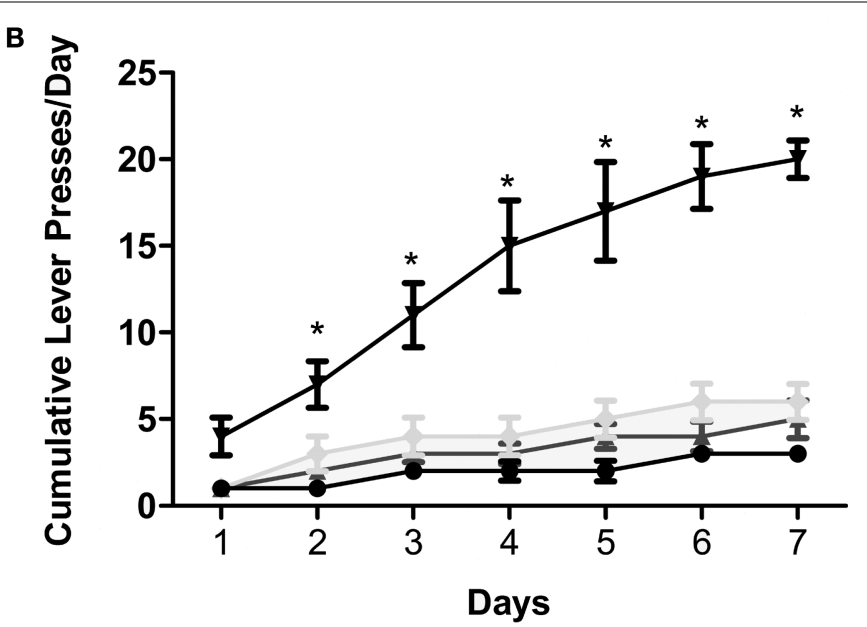

induces lever-pressing in the hippocampus and not the cortex (CTX). All groups were co-treated with $100 \mu \mathrm{M} \mathrm{SCH} 23390$ during days 5-7. Intrahippocampal METH group active lever presses were significantly greater than CTX METH and Ringer's vehicle groups from day 2 onward. The symbol * represents a difference from all other groups $(P<0.05)$. Hippocampus METH group: upside-down black triangles; Hippocampus METH inactive: light gray diamonds; Hippocampus Ringer's: dark gray triangles; CTX METH: black filled circles.

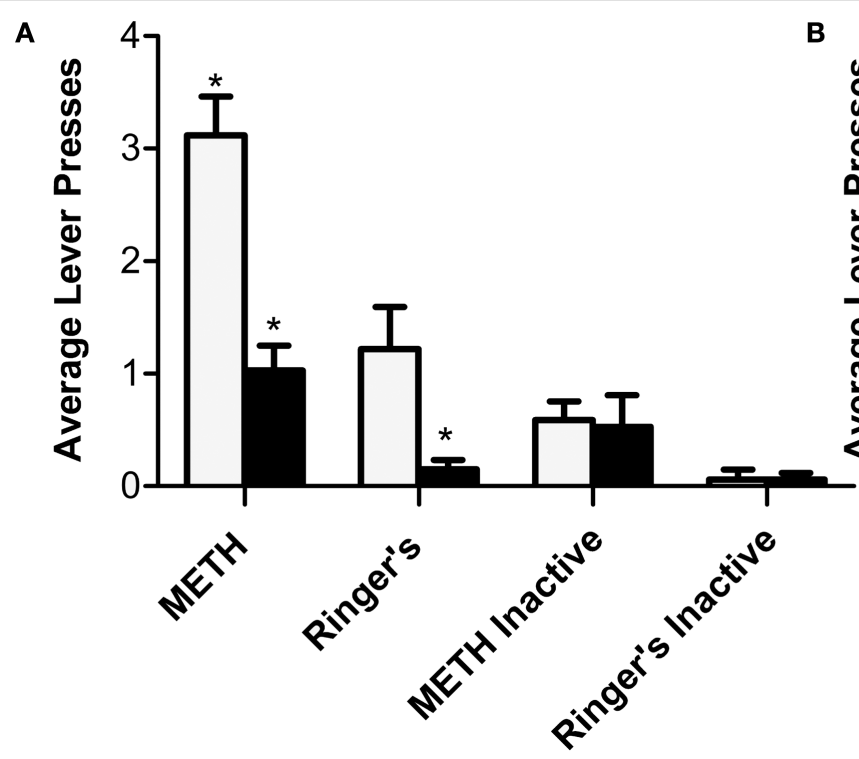

FIGURE 4 | Intrahippocampal METH self administration is modulated via local $\mathbf{D}_{1} / \mathbf{D}_{\mathbf{5}}$ receptors. (A) Average lever presses on the active and inactive levers during the 30 -min test sessions across 7 days. Rats in the Ringer's $(n=12)$ and METH $10 \mu \mathrm{g} / \mu \mathrm{l}(n=17)$ groups were co-treated with $250 \mu \mathrm{M} \mathrm{SCH}$ 23390 during days 5-7 (black bars). METH group active lever presses were significantly greater than Ringer's group active lever presses. Local application of

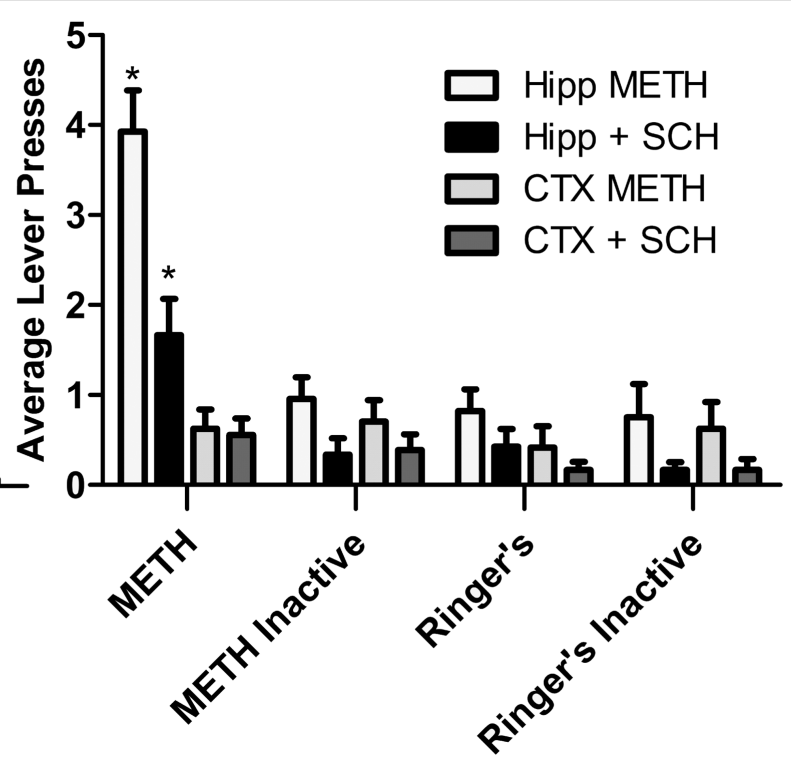

SCH 23390 impairs (black bars) impairs METH lever pressing behavior. (B) METH only induces lever-pressing in the hippocampus and not the cortex (CTX). All groups were co-treated with $100 \mu \mathrm{M} \mathrm{SCH} 23390$ during days 5-7. Intrahippocampal METH group active lever presses were significantly greater than CTX METH and Ringer's vehicle groups from day 2 onward. The symbol * represents a difference from all other groups $(P<0.05)$. study are 10-fold higher than those generally found in brain slice superfusion experiments, and were chosen to compensate for the spatial and temporal limitations associated with drug administration by reverse microdialysis, usually done in other studies (Hoebel et al., 1983; Johnson and Justice, 1983; Kurata and Shibata, 1991; Zornoza et al., 2005b; Rodriguez et al., 2008).

\section{GENERAL DISCUSSION}

The hippocampus is a particularly suitable structure in which to study the role of psychostimulants in light of its exceptional monoaminergic innervation and its support of ICSS (Ursin et al., 1966; German and Bowden, 1974). Very few studies have investigated the neurochemical substrates of intrahippocampal 
electrical self-stimulation behavior (Ursin et al., 1966). In one study, lesioning the locus coeruleus failed to disrupt intrahippocampal electrical self-stimulation (van der Kooy et al., 1977). Interestingly, hippocampal lesions lowered intra-VTA electrical self-stimulation (Van Wolfswinkel and Van Ree, 1984). Another study showed that microinfusion of amphetamine into the NAc enhanced intra-subiculum electrical stimulation rates (Sweet and Neill, 1999). Remarkably, there are only few reports of intracranial CPP (Corrigall and Linseman, 1988) and self administration of drugs directly into the hippocampus (Stevens et al., 1991). In this respect, the hippocampus remains largely unexplored in the context of local drug-induced reinforcement, despite considerable neuroanatomical and neurochemical observations indicating the presence of potential neurotransmitters that are known to be important in drug reinforcement.

Here, we show the first demonstration that the hippocampus is a site for METH-induced (via reverse microdialysis) CPP and lever-pressing behavior. The data reported herein supports other hippocampal electrical stimulation findings (Ursin et al., 1966), and in vitro slice physiological experiments (Corrigall and Linseman, 1980, 1988; Linseman and Corrigall, 1981, 1982, 1984; Stevens et al., 1991) suggesting a role for the hippocampus in drug reward/ reinforcement. Furthermore, we show that the METH-induced drug-seeking and drug-taking behaviors are mediated at least in part via $\mathrm{D}_{1} / \mathrm{D}_{5}$ receptors. The evidence shows that intrahippocampal dialysis of SCH 23390 impairs local METH-induced CPP acquisition while completely blocking CPP expression and effectively impairing lever pressing behavior. Interestingly, others have reported that local blockade of hippocampal $D_{1} / D_{5}$ receptors by pharmacological inactivation with the same selective DA antagonist used here (SCH 23390) also impairs the acquisition and retrieval of systemic morphine-mediated (Rezayof et al., 2003, 2007; Zarrindast et al., 2005) and ethanol-mediated (Rezayof et al., 2007) CPP. In addition, recent evidence suggests a role for the hippocampus in modulating reward via the NAc (Van Wolfswinkel and Van Ree, 1984; Mittleman et al., 1998; Bardgett and Henry, 1999; Taepavarapruk et al., 2000; Gimenez-Llort et al., 2002; Taepavarapruk and Phillips, 2003; Zornoza et al., 2005a,b). Specifically, some studies examined the role of hippocampal DA receptors. For example, one report revealed that the intrahippocampal application of the $\mathrm{D}_{1} / \mathrm{D}_{5}$ receptor antagonist SCH $23390(100$ and $250 \mu \mathrm{M})$ via reverse microdialysis caused a decrease in the local NAc extracellular DA concentration in rodents (Zornoza et al., 2005b).

Further, the hippocampus has also been proposed as a site for novelty detection that uses DA as a "signal" (Lisman and Otmakhova, 2001). Recordings from DA cells in monkeys have shown that DA cells respond rapidly with bursts of spikes to "novel" stimuli (Ljungberg et al., 1992) and as the stimuli become familiar, DA neurons no longer show this transient change in activity. The novelty-induced change in DA cell firing activity has been linked

\section{REFERENCES}

Bardgett, M. E., and Henry, J. D. (1999). Locomotor activity and accumbens Fos expression driven by ventral hippocampal stimulation require $\mathrm{D} 1$ and D2 receptors. Neuroscience 94, 59-70.
Bardo,M.T.(1998).Neuropharmacological mechanisms of drug reward: beyond dopamine in the nucleus accumbens. Crit. Rev. Neurobiol. 12, 37-67.

Bardo, M. T., Donohew, R. L., and Harrington, N. G. (1996).

with augmented DA release in the hippocampus (Ihalainen et al., 1999), which facilitates hippocampal CA1 LTP induction. Not surprisingly, hippocampal application of DA agonists in naïve rats also facilitates LTP induction and enhances learning (Li et al., 2003). Dopaminergic facilitation of learning has been well demonstrated by examining the role of DA receptors in memory facilitation on various learning tasks (Packard and White, 1989, 1991).

It is known that the hippocampus projects to the NAc onto medium spiny neurons. Medium spiny neurons display a bistable subthreshold membrane property (O’Donnell and Grace, 1995). The up-state can be induced by activation of hippocampal afferent fibers onto NAc (O'Donnell and Grace, 1998). In our study, it is likely that the intrahippocampal METH dialysis increases local hippocampal extracellular DA concentration translating into an increased hippocampal afferent input to the NAc sufficient to induce the NAc medium spiny cell's up-state removing VP tonic inhibition onto VTA DA neurons (Lisman and Otmakhova, 2001; Lisman and Grace, 2005).VTA DA neuron activity states are modulated depending on their distinct afferent pathways (Floresco et al., 2003). Thus, overall DA neuron burst firing induce large transient elevations in synaptic DA release in NAc (Chergui et al., 1994) and hippocampus (Ihalainen et al., 1999) and considered to be the postsynaptic signals encoding reward prediction (Schultz, 1998), indicate incentive salience (Berridge and Robinson, 1998); and novelty detection (Ihalainen et al., 1999). In fact, a recent study showed that the hippocampus indeed modulates DA neuron responsivity by regulating the intensity of phasic neuron activation (Lodge and Grace, 2006). Local transient increases in hippocampal DA levels are known to trigger downstream second messenger systems resulting in gene expression and protein synthesis enabling long-lasting changes in synaptic plasticity such as enhanced LTP in the hippocampus CA1 region following cocaine self administration (Thompson et al., 2002, 2004, 2005; del Olmo et al., 2006a,b; Swant and Wagner, 2006).

Taken together, the results suggest a role for the hippocampus in drug-seeking (CPP) and drug-taking behavior (self administration). Further, we found that both of these behaviors are modulated in part by local hippocampal $\mathrm{D}_{1} / \mathrm{D}_{5}$ receptors. These results implicate the hippocampus as a significant site for drug reward/reinforcement probably by making use of the anatomical circuit to the VTA via the NAc and VP (Lisman and Grace, 2005). Alternatively, the hippocampus may be a functional link between learning and memory and reinforcement by demonstrating that reinforcement occurs in a structure intimately associated with learning and memory.

\section{ACKNOWLEDGMENTS}

WethankR.Renthalforhisassistancewith the $\left[{ }^{3} \mathrm{H}\right] \mathrm{d}$-methamphetamine diffusion experiment; A. Zavala for valuable comments and discussion. Work supported by grants from the National Institutes of Health (DA 04195 to Joe L. Martinez Jr.; T32MH18882 to Ulises M. Ricoy) and the Ewing Halsell Endowment to Joe L. Martinez Jr.

Psychobiology of novelty seeking and drug seeking behavior. Behav. Brain Res. 77, 23-43.

Bazzett, T. J., Becker, J. B., and Albin, R. L. (1991). A novel device for chronic intracranial drug delivery via micro- dialysis. J. Neurosci. Methods 40, 1-8.

Berke, J. D. (2003). Learning and memory mechanisms involved in compulsive drug use and relapse. Methods Mol. Med. 79, 75-101. 
Berke, J.D., and Eichenbaum,H. B. (2001). Drug addiction and the hippocampus. Science (New York) 294, 1235.

Berke, J. D., and Hyman, S. E. (2000). Addiction, dopamine, and the molecular mechanisms of memory. Neuron 25, 515-532.

Berridge, K. C., and Robinson, T. E. (1998). What is the role of dopamine in reward: hedonic impact, reward learning, or incentive salience? Brain Res. Brain Res. Rev. 28, 309-369.

Bischoff, S., Bittiger, H., and Krauss, J. (1980). In vivo [3H] spiperone binding to the rat hippocampal formation: involvement of dopamine receptors. Eur. J. Pharmacol. 68, 305-315.

Black, Y.D., Green-Jordan, K., Eichenbaum, H. B., and Kantak, K. M. (2004). Hippocampal memory system function and the regulation of cocaine selfadministration behavior in rats. Behav. Brain Res. 151, 225-238.

Blaha, C. D., Yang, C. R., Floresco, S. B., Barr, A. M., and Phillips, A. G. (1997). Stimulation of the ventral subiculum of the hippocampus evokes glutamate receptor-mediated changes in dopamine efflux in the rat nucleus accumbens. Eur. J. Neurosci. 9, 902-911.

Bruinink, A., and Bischoff, S. (1986). Detection of dopamine receptors in homogenates of rat hippocampus and other brain areas. Brain. Res. 386, 78-83.

Chergui, K., Suaud-Chagny, M. F., and Gonon, F. (1994). Nonlinear relationship between impulse flow, dopamine release and dopamine elimination in the rat brain in vivo. Neuroscience 62 , 641-645.

Collier, T. J., Kurtzman, S., and Routtenberg, A. (1977). Intracranial self-stimulation derived from entorhinal cortex. Brain Res. 137, 188-196.

Collier, T. J., Miller, J. S., Travis, J., and Routtenberg, A. (1982). Dentate gyrus granule cells and memory: electrical stimulation disrupts memory for places rewarded. Behav. Neural Biol. 34, 227-239.

Collier, T. J., and Routtenberg, A. (1984). Electrical self-stimulation of dentate gyrus granule cells. Behav. Neural Biol. 42, 85-90.

Corrigall, W. A., and Linseman, M. A. (1980). A specific effect of morphine on evoked activity in the rat hippocampal slice. Brain Res. 192, 227-238.

Corrigall, W. A., and Linseman, M. A. (1988). Conditioned place preference produced by intra-hippocampal morphine. Pharmacol. Biochem. Behav. 30, 787-789.

Crespo, J. A., Sturm, K., Saria, A., and Zernig, G. (2006). Activation of muscarinic and nicotinic acetylcholine receptors in the nucleus accumbens core is necessary for the acquisition of drug reinforcement. J. Neurosci. 26, 6004-6010.

del Olmo, N., Higuera-Matas, A., Miguens, M., Garcia-Lecumberri, C., Borcel, E., Solis, J.M., and Ambrosio, E. (2006a). Hippocampal synaptic plasticity and water maze learning in cocaine self-administered rats. Ann. N. Y. Acad. Sci. 1074, 427-437.

del Olmo, N., Miguens, M., HigueraMatas, A., Torres, I., GarciaLecumberri, C., Solis, J. M., and Ambrosio, E. (2006b). Enhancement of hippocampal long-term potentiation induced by cocaine selfadministration is maintained during the extinction of this behavior. Brain Res. 1116, 120-126.

Floresco, S. B., West, A. R., Ash, B., Moore, H., and Grace, A. A. (2003). Afferent modulation of dopamine neuron firing differentially regulates tonic and phasic dopamine transmission. Nat. Neurosci. 6, 968-973.

Gasbarri,A., Packard, M. G., Campana, E., and Pacitti, C. (1994a). Anterograde and retrograde tracing of projections from the ventral tegmental area to the hippocampal formation in the rat. Brain Res. Bull. 33, 445-452.

Gasbarri, A., Verney, C., Innocenzi, R., Campana, E., and Pacitti, C. (1994b). Mesolimbic dopaminergic neurons innervating the hippocampal formation in the rat: a combined retrograde tracing and immunohistochemical study. Brain Res. 668, 71-79.

German, D. C., and Bowden, D. M. (1974). Catecholamine systems as the neural substrate for intracranial self-stimulation: a hypothesis. Brain Res. 73, 381-419.

Gimenez-Llort, L., Wang, F. H., Ogren, S. O., and Ferre, S. (2002). Local dopaminergic modulation of the motor activity induced by $\mathrm{N}$-methyl-D-aspartate receptor stimulation in the ventral hippocampus. Neuropsychopharmacology 26 737-743.

Gonzales, R. A., McNabb, J., Yim, H. J., Ripley, T., and Bungay, P. M. (1998). Quantitative microdialysis of ethanol in rat striatum. Alcohol Clin. Exp. Res. 22, 858-867.

Groenewegen, H. J., Vermeulen-Van der Zee, E., te Kortschot, A., and Witter, M. P. (1987). Organization of the projections from the subiculum to the ventral striatum in the rat. A study using anterograde transport of Phaseolus vulgaris leucoagglutinin. Neuroscience 23, 103-120.

Hirase, H., Leinekugel, X., Csicsvari, J., Czurko, A., and Buzsaki, G. (2001). Behavior-dependent states of the hippocampal network affect functional clustering of neurons. J. Neurosci. 21, RC145.

Hocht, C., Opezzo, J. A., and Taira, C. A. (2004). Microdialysis in drug discovery. Curr. Drug Discov. Technol. 1, 269-285.

Hocht, C., Opezzo, J. A., and Taira, C. A. (2007).Applicability of reverse microdialysis in pharmacological and toxicological studies. J. Pharmacol. Toxicol. Methods 55, 3-15.

Hoebel, B.G., Monaco,A.P.,Hernandez, L. Aulisi, E. F., Stanley, B. G., and Lenard, L. (1983). Self-injection of amphetamine directly into the brain. Psychopharmacology (Berl.) 81, 158-163.

Hyman, S. E., Malenka, R. C., and Nestler, E. J. (2006). Neural mechanisms of addiction: the role of reward-related learning and memory. Annu. Rev. Neurosci. 29, 565-598.

Ihalainen, J. A., Riekkinen, P. Jr., and Feenstra, M.G. (1999). Comparison of dopamine and noradrenaline release in mouse prefrontal cortex, striatum and hippocampus using microdialysis. Neurosci. Lett. 277, 71-74.

Johnson, R. D., and Justice, J. B. (1983). Model studies for brain dialysis. Brain Res. Bull. 10, 567-571.

Kalisch, R., Schubert, M., Jacob, W. Kessler, M.S., Hemauer, R., Wigger, A., Landgraf, R., and Auer, D. P. (2006). Anxiety and hippocampus volume in the rat. Neuropsychopharmacology 31, 925-932.

Kelley, A. E. (2004). Memory and addiction: shared neural circuitry and molecular mechanisms. Neuron 44, 161-179.

Kurata, K., and Shibata, R. (1991). Effects of D1 and D2 antagonists on the transient increase of dopamine release by dopamine agonists by means of brain dialysis. Neurosci. Lett. 133, 77-80.

Lansink, C. S., Goltstein, P. M., Lankelma, J.V., McNaughton, B. L., and Pennartz, C. M. (2009). Hippocampus leads ventral striatum in replay of placereward information. PLoS Biol. 7 e1000173. doi: 10.1371/journal. pbio. 1000173.

Li, S., Cullen, W. K., Anwyl, R., and Rowan, M. J. (2003). Dopamine-dependent facilitation of LTP induction in hippocampal CA1 by exposure to spatial novelty. Nat. Neurosci. 6, 526-531.

Linseman, M. A., and Corrigall, W. A. (1981). Are endogenous opiates involved in potentiation of field potentials in the hippocampus of the rat? Neurosci. Lett. 27, 319-324.

Linseman, M. A., and Corrigall, W. A. (1982). Effects of morphine on CA1 versus dentate hippocampal field potentials following systemic administration in freely-moving rats. Neuropharmacology 21, 361-366.
Linseman, M. A., and Corrigall, W. A. (1984). Effects of morphine and naloxone on hippocampal CA3 field potentials following systemic administration in the freely-moving rat. Brain Res. Bull. 13, 241-245.

Lisman, J. E., and Grace, A. A. (2005). The hippocampal-VTA loop: controlling the entry of information into long-term memory. Neuron 46, 703-713.

Lisman,J.E., and Otmakhova, N.A.(2001). Storage, recall, and novelty detection of sequences by the hippocampus: elaborating on the SOCRATIC model to account for normal and aberrant effects of dopamine. Hippocampus 11, 551-568.

Ljungberg, T., Apicella, P., and Schultz, W. (1992). Responses of monkey dopamine neurons during learning of behavioral reactions. J. Neurophysiol. 67, 145-163.

Lodge, D. J., and Grace, A. A. (2006). The hippocampus modulates dopamine neuron responsivity by regulating the intensity of phasic neuron activation. Neuropsychopharmacology 31, 1356-1361.

Loy, R., Koziell, D. A., Lindsey, J. D., and Moore, R. Y. (1980). Noradrenergic innervation of the adult rat hippocampal formation. J. Comp. Neurol. 189, 699-710.

Martres, M. P., Sales, N., Bouthenet, M. L., and Schwartz, J.C. (1985). Localisation and pharmacological characterisation of D-2 dopamine receptors in rat cerebral neocortex and cerebellum using [125I]iodosulpride. Eur. J. Pharmacol. 118, 211-219.

Meyers, R. A., Zavala, A. R., and Neisewander, J. L. (2003). Dorsal, but not ventral, hippocampal lesions disrupt cocaine place conditioning. Neuroreport 14, 2127-2131.

Meyers, R. A., Zavala, A. R., Speer, C. M., and Neisewander, J. L. (2006). Dorsal hippocampus inhibition disrupts acquisition and expression, but not consolidation, of cocaine conditioned place preference. Behav. Neurosci. 120, 401-412.

Mittleman, G., Bratt, A. M., and Chase, R. (1998). Heterogeneity of the hippocampus: effects of subfield lesions on locomotion elicited by dopaminergic agonists. Behav. Brain Res. 92, 31-45.

Nestler, E. J. (2001). Neurobiology. Total recall-the memory of addiction. Science (New York) 292, 2266-2267.

Nestler, E. J. (2002). Common molecular and cellular substrates of addiction and memory. Neurobiol. Learn. Mem. 78, 637-647.

Nestler, E. J., and Aghajanian, G. K. (1997). Molecular and cellular basis of addiction. Science (New York) 278, 58-63.

O'Donnell, P., and Grace, A. A. (1995). Synaptic interactions among excitatory 
afferents to nucleus accumbens neurons: hippocampal gating of prefrontal cortical input. J. Neurosci. 15(Pt. 1), 3622-3639.

O'Donnell, P., and Grace, A. A. (1998). Phencyclidine interferes with the hippocampal gating of nucleus accumbens neuronal activity in vivo. Neuroscience 87, 823-830.

Otmakhova, N. A., and Lisman, J. E. (1996). D1/D5 dopamine receptor activation increases the magnitude of early long-term potentiation at CA1 hippocampal synapses. J. Neurosci. 16, 7478-7486.

Otmakhova, N. A., and Lisman, J. E. (1998). D1/D5 dopamine receptors inhibit depotentiation at CA1 synapses via cAMP-dependent mechanism. J. Neurosci. 18, 1270-1279.

Otmakhova, N. A., and Lisman, J. E. (1999). Dopamine selectively inhibits the direct cortical pathway to the CAl hippocampal region. J. Neurosci. 19, 1437-1445.

Packard, M. G., and White, N. M. (1989). Memory facilitation produced by dopamine agonists: role of receptor subtype and mnemonic requirements. Pharmacol. Biochem. Behav. 33, 511-518.

Packard, M. G., and White, N. M. (1991). Dissociation of hippocampus and caudate nucleus memory systems by posttraining intracerebral injection of dopamine agonists. Behav. Neurosci. 105, 295-306.

Paxinos, G., and Watson, C. (2007). The rat brain in stereotaxic coordinates. Amsterdam/Boston, Elsevier.

Plock, N., and Kloft, C. (2005). Microdialysis - theoretical background and recent implementation in applied life-sciences. Eur. J. Pharm. Sci. 25, 1-24.

Quan, N., and Blatteis, C. M. (1989). Microdialysis: a system for localized drug delivery into the brain. Brain Res. Bull. 22, 621-625.

Rezayof, A., Motevasseli, T., Rassouli, Y., and Zarrindast, M. R. (2007). Dorsal hippocampal dopamine receptors are involved in mediating ethanol state-dependent memory. Life Sci. 80, 285-292.

Rezayof, A., Zarrindast, M. R., Sahraei, H., and Haeri-Rohani, A. (2003). Involvement of dopamine receptors of the dorsal hippocampus on the acquisition and expression of morphineinduced place preference in rats. $J$. Psychopharmacol. 17, 415-423.

Robbins, T. W., and Everitt, B. J. (2002). Limbic-striatal memory systems and drug addiction. Neurobiol. Learn. Mem. 78, 625-636.

Robinson, D. L., Lara, J. A., Brunner, L. J., and Gonzales, R. A. (2000). Quantification of ethanol concentrations in the extracellular fluid of the rat brain: in vivo calibration of microdialysis probes. J. Neurochem. 75, 1685-1693.

Rodriguez, J. S., Boctor, S. Y., Phelix, C. F., and Martinez,J.L.Jr. (2008). Differences in performance between SpragueDawley and Fischer 344 rats in positive reinforcement tasks. Pharmacol. Biochem. Behav. 89, 17-22.

Scatton, B., Simon, H., Le Moal, M., and Bischoff, S. (1980). Origin of dopaminergic innervation of the rat hippocampal formation. Neurosci. Lett. 18, 125-131.

Schultz,W.(1998).Predictive reward signal of dopamine neurons. J. Neurophysiol. 80, 1-27.

Stevens, K. E. (1989). Hippocampal substrates of reinforcement: a pharmacological analysis of hippocampal self-stimulation and selfadministration. Diss. Abstr. Int. 50. 14-35, 83-102.

Stevens, K. E., Shiotsu, G., and Stein, L. (1991). Hippocampal mu-receptors mediate opioid reinforcement in the CA3 region. Brain Res. 545, 8-16.

Sun, W., and Rebec, G.V. (2003). Lidocaine inactivation of ventral subiculum attenuates cocaine-seeking behavior in rats. J. Neurosci. 23, 10258-10264.

Swanson, L.W. (1982). The projections of the ventral tegmental area and adjacent regions: a combined fluorescent retrograde tracer and immunofluorescence study in the rat. Brain Res. Bull. 9, 321-353.

Swant, J., and Wagner, J. J. (2006). Dopamine transporter blockade increases LTP in the CA1 region of the rat hippocampus via activation of the D3 dopamine receptor. Learn. Mem. 13, 161-167.

Sweet, K. L., and Neill, D. B. (1999). Amphetamine injections into the nucleus accumbens enhance the reward of stimulation of the subiculum. Ann. N. Y. Acad. Sci. 877, 828-830.

Taepavarapruk, P., Floresco, S. B., and Phillips,A.G.(2000).Hyperlocomotion and increased dopamine efflux in the rat nucleus accumbens evoked by electrical stimulation of the ventral subiculum: role of ionotropic glutamate and dopamine D1 receptors. Psychopharmacology (Berl.) 151, 242-251.
Taepavarapruk, P., and Phillips, A. G. (2003). Neurochemical correlates of relapse to d-amphetamine selfadministration by rats induced by stimulation of the ventral subiculum. Psychopharmacology (Berl.) 168, 99-108.

Thompson, A. M., Gosnell, B. A., and Wagner, J. J. (2002). Enhancement of long-term potentiation in the rat hippocampus following cocaine exposure. Neuropharmacology 42 , 1039-1042.

Thompson, A. M., Swant, J., Gosnell, B.A., and Wagner, J. J. (2004). Modulation of long-term potentiation in the rat hippocampus following cocaine selfadministration. Neuroscience 127 , 177-185.

Thompson, A. M., Swant, J., and Wagner, J. J. (2005). Cocaine-induced modulation of long-term potentiation in the CA1 region of rat hippocampus. Neuropharmacology 49, 185-194.

Tzschentke, T. M. (1998). Measuring reward with the conditioned place preference paradigm: a comprehensive review of drug effects, recent progress and new issues. Prog. Neurobiol. 56, 613-672.

Ursin, R., Ursin, H., and Olds, J. (1966) Self-stimulation of hippocampus in rats. J. Comp. Physiol. Psychol. 61, 353-359.

van der Kooy, D., Fibiger, H. C., and Phillips, A. G. (1977). Monoamine involvement in hippocampal selfstimulation. Brain Res. 136, 119-130.

Van Wolfswinkel, L., and Van Ree, J. M. (1984).Hippocampus modulates selfstimulation reward from the ventral tegmental area in the rat. Brain Res. 322, 162-166.

Verney, C., Baulac, M., Berger, B., Alvarez, C., Vigny, A., and Helle, K. B. (1985). Morphological evidence for a dopaminergic terminal field in the hippocampal formation of young and adult rat. Neuroscience 14, 1039-1052.

Vezina, P., Lorrain, D. S., Arnold, G. M., Austin, J. D., and Suto, N. (2002) Sensitization of midbrain dopamine neuron reactivity promotes the pursuit of amphetamine. J. Neurosci. 22, 4654-4662.

Vorel, S. R., Liu, X., Hayes, R. J., Spector, J. A., and Gardner, E. L. (2001). Relapse to cocaine-seeking after hippocampal theta burst stimulation. Science (New York) 292, 1175-1178.

Wise, R. A., Newton, P., Leeb, K., Burnette, B.,Pocock,D., and Justice,J.B.Jr.(1995). Fluctuations in nucleus accumbens dopamine concentration during intravenous cocaine self-administration in rats. Psychopharmacology (Berl). 120, 10-20.

Wolf, M. E. (2002). Addiction: making the connection between behavioral changes and neuronal plasticity in specific pathways. Mol. Interv. 2, 146-157.

Wozniak, K. M., Pert, A., Mele, A., and Linnoila, M. (1991). Focal application of alcohols elevates extracellular dopamine in rat brain: a microdialysis study. Brain Res. 540, 31-40.

Zarrindast, M. R., Nasehi, M., Rostami, P. Rezayof, A., and Fazli-Tabaei, S. (2005). Repeated administration of dopaminergic agents in the dorsal hippocampus and morphine-induced place preference. Behav. Pharmacol. $16,85-92$.

Zornoza, T., Cano-Cebrian, M. J., Martinez-Garcia, F., Polache, A., and Granero, L. (2005a). Hippocampal dopamine receptors modulate cFos expression in the rat nucleus accumbens evoked by chemical stimulation of the ventral hippocampus. Neuropharmacology 49, 1067-1076.

Zornoza, T., Cano-Cebrian, M. J., Miquel, M., Aragon, C., Polache, A., and Granero, L. (2005b). Hippocampal dopamine receptors modulate the motor activation and the increase in dopamine levels in the rat nucleus accumbens evoked by chemical stimulation of the ventral hippocampus. Neuropsychopharmacology 30, 843-852.

Conflict of Interest Statement: The authors declare that the research was conducted in the absence of any commercial or financial relationships that could be construed as a potential conflict of interest.

Received: 04 September 2009; paper pending published: 13 October 2009; accepted: 29 October 2009; published online: 16 November 2009.

Citation: Ricoy UM and Martinez JL Jr. (2009) Local hippocampal methamphetamine-induced reinforcement. Front. Behav. Neurosci. 3:47. doi: 10.3389/neuro.08.047.2009

Copyright (C) 2009 Ricoy and Martinez Jr. This is an open-access article subject to an exclusive license agreement between the authors and the Frontiers Research Foundation, which permits unrestricted use, distribution, and reproduction in any medium, provided the original authors and source are credited. 